\title{
Instituições do poder local no Brasil e em Angola
} Local power institutions in Brazil and Angola

\section{Janaína Rigo Santin}

${ }^{1}$ Universidade de Passo Fundo, Passo Fundo, Rio Grande do Sul, Brasil. Universidade de Caxias do Sul, Caxias do Sul, Rio Grande do Sul, Brasil. E-mail: janainars@upf.br. ORCID: http://orcid.org/0000-0001-6547-2752.

\section{Carlos Teixeira²}

2 Universidade Agostinho Neto, Luanda, Angola. Juiz Conselheiro do Tribunal Constitucional Angolano. E-mail: cteixeira1611@hotmail.com. https://orcid.org/00000001-7586-1911.

Artigo recebido em 16/08/2019 e aceito em 9/09/2019.

\section{$(\mathrm{cc}) \mathrm{BY}$}

This work is licensed under a Creative Commons Attribution 4.0 International License 


\section{Resumo}

Este artigo busca estudar as instituições angolanas de Poder Local, comparando-as com o que se tem a respeito do Poder Local no ordenamento jurídico brasileiro. O Poder Local está explícito na Constituição angolana de 2010, e implícito no texto constitucional brasileiro, quando eleva o Município a ente federativo e estabelece formas participativas de exercício do poder político em âmbito local. Porém, não basta apenas o reconhecimento formal do Poder Local, é preciso desenvolver uma cultura participativa, ainda incipiente em ambos os países.

Palavras-chave: Angola; Participação; Poder Local.

\section{Abstract}

This paper study the Angolan institutions of Local Government, comparing them with what has to do with Local Government in the Brazilian legal system. Local Power is explicit in the 2010' Angola Constitution, and implicit in the Brazilian constitutional text, when it elevates the Municipality to a federative entity and establishes participatory forms of exercise of political power at the local level. However, not only formal recognition of Local Government is enough, it is necessary to develop a participatory culture, still incipient in both countries

Keywords: Angola; Participation; Local power. 


\section{Introdução}

Atualmente, quase a totalidade dos países mundiais se afirma democrática. O conceito de Democracia advém de toda uma tradição histórica, por meio de tentativas de acerto, prova e erro, em que cada conceito tem sua história e que essa história está relacionada com o destino das sociedades e de suas organizações políticas. Mas afirma Giovanni Sartori ${ }^{1}$ que ao se tentar definir a Democracia, não é possível se satisfazer com esse conhecimento herdado, mas sim a partir dele construir algo novo. Aprender com o passado com olhos para o futuro, a fim de se buscar não o que a Democracia foi, mas o que ela pode e deve ser.

A Democracia é um ideal de todas as nações, um processo de busca, em que novos valores vão sendo incorporados, com o rompimento dos contrários e que, como tal, ela nunca se realiza inteiramente, pois a cada nova conquista feita abrem-se outras perspectivas, novos horizontes ao seu aperfeiçoamento. Cada nação deve encontrar o seu caminho, de acordo com a época vivenciada e o lugar, a cultura, as tradições, segundo o nível e caráter do seu povo. Mas é consenso geral de que tudo leva às formas democráticas, como ideal maior, o qual marcha lado a lado com o reconhecimento do princípio da participação popular e a afirmação de que o poder emana do povo e para ele deve ser exercido.

É impossível a Democracia prescindir da representação, ante a magnitude dos Estados contemporâneos, totalmente diferentes das polis gregas. As eleições são fundamentais, como um procedimento instrumental da expressão da confiança popular em seus representantes. Mas não absorvem a plenitude da Democracia, que deve ser mantida viva durante toda a gestão pública do eleito. Assim, para efetivar realmente a Democracia é preciso que o povo imponha limites e controle efetivos do poder, podendo impugnar sua atuação pelo caráter crítico, aberto e dialógico que devem possuir as sociedades democráticas.

Entretanto, não basta apenas o controle do poder. É preciso também que o povo participe do poder, indo além da representação, para conjugar-se a Democracia representativa com a Democracia participativa. Não se pode resumir a Democracia apenas no poder do povo em eleger seus representantes periodicamente. Além disso, a

\footnotetext{
${ }^{1}$ SARTORI, Giovanni. Teoría de la Democracia: 2. Los problemas clásicos. Tradução de: Santiago Sánchez González. Madrid: Alianza Editorial, 1997.
} 
participação eleitoral é apenas uma das formas de participação. Essa concepção favorece o desinteresse sistemático dos administrados pela vida política, favorece a apatia, a abstenção, a resignação ante a corrupção, a falta de confiança nos governantes e a abdicação da participação na vida pública, fatores que corroem o ideal democrático. Tal é a realidade constatada nos dois países aqui estudados, Brasil e Angola, os quais possuem uma história comum e também a língua oficial comum, bem como comungam da necessidade de fortalecer suas instituições democráticas.

O que se busca estudar aqui é a categoria do Poder Local, o qual é apontado nos dois países estudados como "uma possível solução, mediante processos de descentralização, de participação e de autonomia em âmbito municipal ou regional. Cada cidadão assume, conjuntamente com os governantes, o ônus e o bônus de assegurar seus direitos elementares, mediante gestões democráticas participativas locais." ${ }^{2}$ Trata-se, portanto, de um novo paradigma de gestão pública, capaz de aliar participação com descentralização, valorizando-se o pluralismo ${ }^{3}$ que existe tanto em Angola quanto no Brasil. Em Angola, o Poder Local está positivado em vários momentos na Constituição da República de Angola de 2010, em especial em seu artigo 213 e seguintes, e engloba as instituições do poder tradicional, as autarquias locais e outras modalidades específicas de participação dos cidadãos. Já no Brasil, o Poder Local encontra-se implícito, derivado do princípio democrático (art. 1.o parágrafo único da Constituição Brasileira de 1988) e da previsão constitucional de elevação do Município a ente federativo, com autonomia política, administrativa, financeira e legislativa, com competências e poderes próprios.

Assim, pelo método dedutivo, o presente artigo tenciona problematizar a questão do Poder Local no Brasil e também em Angola, analisando as instituições que o compõe em ambos os países e o grau de efetividade que elas apresentam. Salienta-se que Angola e Brasil possuem um passado e uma língua em comum, além de inúmeros elementos culturais, o respeito à diversidade, a música, as cores, as crenças e a alegria de viver de seus povos.

\footnotetext{
2 SANTIN, Janaína Rigo. Estado, Constituição e Administração Pública no Século XXI: novos desafios da cidadania e do Poder Local. Belo Horizonte: Arraes, 2017.

${ }^{3}$ Nesse contexto do pluralismo e poder local, a matriz teórica adotada parte-se, em Angola, de: SANTOS, Boaventura de Sousa; VAN DÚNEN, José Octávio Serra. Sociedade e Estado em Construção: desafios do direito e da democracia em Angola. Coimbra: Almedina, 2012. E, no Brasil, de: DOWBOR, Ladislau. O que é poder local. São Paulo: Brasiliense, 1994 e WOLKMER, Antônio Carlos. Pluralismo jurídico: fundamentos de uma nova cultura no Direito. São Paulo: Alfa Ômega, 1997.
} 


\section{Poder Local no Brasil}

A promulgação da Constituição Federal de 1988 faz parte de um processo que atribuiu autonomia política, legislativa, administrativa e financeira para as municipalidades. Instaurou-se uma ordem fundamentada na ideia de que o Estado, impositivo sobre uma comunidade subordinada, deveria ser substituído pelo desenvolvimento de uma vida ativa politicamente por parte dos seus cidadãos, tanto individual quanto coletivamente considerados. Esse fator pode ser observado até mesmo com a Assembleia Constituinte que originou a Constituição de 1988, eis que contou com a participação de vários segmentos da sociedade, revitalizando o processo de democratização da vida pública, obstado pelo regime militar. ${ }^{4}$

A atual Carta Política Brasileira optou pela descentralização da administração pública, a conferir, como nenhuma antes, verdadeira autonomia ao ente municipal, garantindo-Ihe todas as prerrogativas do princípio federativo. Também aumentou as atribuições à entidade federativa municipal, com vistas a tornar os serviços prestados à população mais eficientes e garantir, assim, o atendimento de suas necessidades. Inovou por integrar o Município a ente de terceiro grau na Federação Brasileira, e sua autonomia foi ampliada em quatro aspectos: político, administrativo, legislativo e financeiro. Ou seja, a Constituição Federal de 1988 passou a conferir ao Município todos os poderes inerentes à autonomia de um ente federado: poder de auto-organização, poder de autogoverno, poder de auto legislação e poder de autoadministração. $E$, ao mesmo tempo em que garante autonomia municipal, a Constituição Federal de 1988 também estabelece os princípios norteadores da soberania popular, em seu artigo 1. parágrafo único, assegurando constitucionalmente não apenas o povo como titular do poder político, mas também a sua participação no exercício deste poder, nos termos da Constituição. Nas palavras de Luciane Moás “A Constituição Federal institucionalizou o poder popular, ou seja, a soberania como única fonte de poder legítimo" ${ }^{5}$.

Assim, a partir de 1988 o Brasil adotou como forma de governo a Democracia semidireta, na qual o povo é o detentor real do poder, mas o exercício do governo se dá por meio de representantes políticos (representação partidária) eleitos periodicamente, os quais devem dividir este poder com os cidadãos, por meio de mecanismos

\footnotetext{
${ }^{4}$ MOÁs, Luciane da Costa. Cidadania e poder local. Rio de Janeiro: Lumen Juris, 2002. p. 44.

${ }^{5}$ MOÁS, Luciane da Costa. Cidadania e poder local. Rio de Janeiro: Lumen Juris, 2002. p. 53.
} 
participativos normatizados na própria Carta (art. 14 da Constituição Federal). Ou seja, além da tradicional participação política indireta, (por via da representação, com pluripartidarismo e sufrágio universal), no Brasil é possível realizar a participação do povo no exercício do poder político tanto no Poder Executivo quanto no Legislativo e o Judiciário.

No Poder Legislativo percebe-se o princípio da participação no artigo 14 da Magna Carta, por meio dos seguintes institutos: a) o plebiscito: o povo é chamado a decidir por meio de votação sobre mudança a ser introduzida nas instituições estatais (art. 14, 1); b) o referendo: submeter à apreciação do povo decisões de seus representantes, que serão ratificadas ou não (art. 14, II); e c) a iniciativa popular: o povo pleiteia coletivamente seus interesses perante seus representantes, apresentando projeto de lei firmado por percentual representativo dos cidadãos (art. 14, III). Além disso, é preciso ressaltar a obrigatória participação da população na elaboração, em âmbito municipal, do Plano Diretor (artigo 182 da Constituição Federal de 1988 e Lei 10.257/2001) e nas leis orçamentárias (Lei Complementar n. 101/2000).

Já no Poder Executivo a participação da população se dá por meio dos conselhos municipais, os quais possibilitam que entidades da sociedade civil e os próprios munícipes possam participar da elaboração das políticas públicas municipais na área da saúde, meio ambiente, educação, planejamento urbano, desenvolvimento econômico, idosos, dentre outros. Também é no executivo municipal que podem ser instaladas as ouvidorias, ou ombudsman, que é um setor responsável por fazer a mediação entre os cidadãos e os órgãos da administração direta e indireta municipal, com vistas a levar queixas de má prestação dos serviços públicos aos órgãos competentes.

Por fim, no Poder Judiciário pode-se perceber os seguintes mecanismos de participação dos cidadãos na tomada das decisões judiciais: julgamentos de crimes dolosos contra a vida são realizados pelo júri popular; juízes leigos, conciliadores e mediadores, os quais são pessoas da comunidade e/ou advogados, que fazem funções jurisdicionais em causas cíveis de menor valor ou crimes de menor gravidade; amicus curiae, representante da sociedade civil em cortes superiores, que vai defender interesses específicos em processos de alta repercussão. Conforme o entendimento de Cláudio Ladeira de Oliveira e Miguel Etinger de Araújo

Quando a Constituição determinou que a democracia participativa seria um modelo para o país, e o legislador infraconstitucional operacionalizou-a, 
colocou em prática este modelo, tem-se que a conquista social de participação na gestão das cidades é um avanço da própria sociedade e se o direito constitucional direciona à ampliação desta conquistas, qualquer tentativa de diminuí-las constituirá afronta aos comandos constitucionais. ${ }^{6}$

Assim, o Poder Local no Brasil apresenta-se como um novo paradigma para o exercício do poder, aproximando a gestão administrativa das reais necessidades da sociedade. Esse "espaço local" no Brasil é o Município, unidade básica de organização social, mas também o bairro, o quarteirão em que vive o cidadão. O Município é capaz de autotransformar e auto estruturar sua realidade econômica e social, com a participação de todos de maneira ampla. ${ }^{7}$ Afinal, na instância municipal, as dinâmicas sociais apresentam-se com maior intensidade e os munícipes tornam-se os principais envolvidos com o desfecho das tomadas de decisão governamentais. Serão eles que se beneficiarão com políticas boas ou sofrerão as consequências ruins de uma má administração. Por abranger o centro das relações sociais, a cidade deve ser o foco de discussão no cenário político e o berçário da cidadania, garantindo a participação popular nesse processo de tomada de decisões políticas. ${ }^{8}$

A experiência histórica brasileira demonstrou que os níveis federais e estaduais do governo por grandes períodos isolaram-se em torno de objetivos centralizadores, clientelistas e eleitoreiros, não dispondo maior importância com o bem-estar dos cidadãos. Dominados por elites interessadas em manter a situação social controlada, desenvolveu-se o centralismo das decisões, conseguido à custa da retirada de poder das municipalidades. A manutenção das elites dava-se com o amesquinhamento municipal. Para combater tais fatos

[...] resta o espaço da cidade como um reduto de civilidade racional passível de gestão operativa e mais eficaz, com possibilidades maximizadas de transparência e de controle imediato, bem como de participação societal. Afinal, é na cidade que as pessoas, mal ou bem, constroem seus vínculos de afetividade e de identidade mais imediatos, travando com seus pares relações de integração ou de afastamento cotidianos. Aqui, a sensação de

\footnotetext{
6 OLIVEIRA, Cláudio Ladeira de et ARAÚJO JÚNIOR, Miguel Etinger de. Democracia participativa e plano diretor dos municípios. In: XV Congresso Nacional do CONPEDI, 2007, Belo Horizonte. Anais do XV Congresso Nacional do CONPEDI. Florianópolis : Boiatex, 2007. v. 1. p. 6631-6648. Disponível em http://www.conpedi.org/manaus/arquivos/anais/bh/claudio_ladeira_de_oliveira.pdf. Acesso em 16 ago. 2019.

${ }^{7}$ DOWBOR, Ladislau. O que é poder local. São Paulo: Brasiliense, 1994. p. 11.

8 LEAL, Rogério Gesta. Direito urbanístico: condições e possibilidades da constituição do espaço urbano. Rio de Janeiro: Renovar, 2003. p. 61.
} 
pertencimento a um núcleo orgânico de sujeitos políticos (mesmo a dos excluídos) se faz sentir de maneira mais explícita. ${ }^{9}$

A Democracia participativa, realizada em conjunto com a Democracia representativa, passa a ser regime apropriado para atender as mazelas sociais. Essa constatação será verificada no momento em que a "própria população compreender que é preciso solucionar os problemas e construir a cidade a partir da comunidade, e não receber da administração central soluções técnicas e burocráticas longes da realidade local” ${ }^{10}$. É um poder da comunidade, que poderá desenvolver sua participação nas questões políticas municipais, aliada à administração pública, conjugando assim a Democracia representativa e participativa a partir dos preceitos inaugurados na Carta Magna de 1988.

Quando as decisões são tomadas muito longe do cidadão, correspondem muito pouco às suas necessidades. Assim, a dramática centralização do poder político e econômico que caracteriza a nossa forma de organização como sociedade leva, em última instância, a um divórcio profundo entre nossas necessidades e o conteúdo das decisões sobre o desenvolvimento econômico e social. ${ }^{11}$

O planejamento público deve atender às reais demandas sociais, e isso somente será possível aumentando o diálogo do poder público com os diversos setores da sociedade, incluindo, assim, os cidadãos na gestão municipal. E para que a participação seja efetivada será necessário descentralizar, a fim de que as decisões sejam tomadas a partir de uma aproximação maior do gestor público com os problemas que devem inspirar suas escolhas e decisões.

Ou seja, mesmo que o modelo de descentralização do poder tenha apontado resultados positivos nos países em que foi experimentado (como Espanha, Suíça, Alemanha e Estados Unidos), deve-se atentar para o fato de que lá, de uma maneira ou outra, o Poder Local já era uma realidade vivificada em sua história. A simples importação desse modelo ao sistema brasileiro não é garantia nenhuma de sua real eficácia. Primeiro, porque o Brasil não possui uma história voltada para a descentralização e para o fortalecimento do Poder Local. Muitas de suas instituições políticas ainda mostram-se instáveis e até mesmo vulneráveis a práticas centralizadoras e/ou clientelistas. Além disso, a realidade brasileira (e também a angolana), em especial

\footnotetext{
9 LEAL, Rogério Gesta. Direito urbanístico: condições e possibilidades da constituição do espaço urbano. Rio de Janeiro: Renovar, 2003. p. 69.

${ }_{10}$ MOÁS, Luciane da Costa. Cidadania e poder local. Rio de Janeiro: Lumen Juris, 2002. p. 63.

11 DOWBOR, Ladislau. O que é poder local. São Paulo: Brasiliense, 1994. p. 16.
} 
em decorrência do modelo de colonização adotado, demonstra uma diferença imensa em relação à história dos países desenvolvidos, em especial norte-americanos e da Europa ocidental.

Por outro lado, apesar das dificuldades e da imaturidade da Democracia brasileira, é preciso acreditar no Poder Local como um processo em construção. $O$ instrumental jurídico já está posto. O necessário agora é efetivá-lo. Para enfrentar essa situação, Konrad Hesse ${ }^{12}$ dispõe que é preciso fortalecer a força normativa da Constituição.

\section{Poder Local em Angola}

Angola é um país africano de mais de 25 milhões de habitantes, ${ }^{13}$ localizado na costa ocidental da África, cujo território principal confronta-se ao norte e nordeste com a República Democrática do Congo, a leste pela Zâmbia, a sul pela Namíbia e, a oeste, pelo Oceano Atlântico. Compõe também seu território o exclave de Cabina, situado ao norte, o qual se localiza dentro da República do Congo. Assim como no Brasil, foi colonizada por Portugal, tendo o português como língua oficial, a qual convive com inúmeras outras línguas tradicionais locais.

Sua independência do colonizador é recente, em 11 de novembro de 1975, depois de uma longa guerra de libertação, com a assinatura dos Acordos de Alvor por Portugal e os três movimentos de libertação nacional: MPLA (Movimento Popular de Libertação de Angola), FNLA (Frente Nacional de Libertação de Angola) e UNITA (União Nacional para a Independência Total de Angola), iniciou-se o processo de independência, que se consolidou, conforme Araújo, "às zero horas do dia 11 de Novembro, o Presidente do MPLA, Dr. António Agostinho Neto, proclama a independência de Angola, baptizada de República Popular de Angola, no meio de uma violenta guerra civil". ${ }^{14}$

\footnotetext{
12 HESSE, Konrad. A força normativa da constituição. Tradução de: Gilmar Ferreira Mendes. Porto Alegre: Sérgio Antonio Fabris, 1991. p. 22.

13 RTP Notícias. População de Angola sobe para mais de 25,7 milhões de pessoas. Disponível em: https://www.rtp.pt/noticias/mundo/populacao-de-angola-sobe-para-mais-de-257-milhoes-depessoas_n906065. Acesso em 08 fev. 2018.

14 ARAÚJO, Raul. A Evolução Constitucional das Justiças de Angola. In: SANTOS, Boaventura de Sousa; VAN DÚNEN, José Octávio Serra (Orgs.). Sociedade e Estado em Construção: desafios do direito e da democracia em Angola. v. I. Coimbra: Almedina, 2012. p. 165.
} 
Durante o período de guerra civil o país passou por vários processos políticos, primeiramente do tipo república socialista, com predomínio do monopólio político do partido dirigente, assim como a ideologia marxista, período que se estendeu até 1991, data em que se iniciou o processo de transição democrática, com a edição da Lei Constitucional de 1992 e a realização das primeiras eleições democráticas do país. Este período (1975/1992) é denominado de I. República. Por sua vez, o período que compreende a aprovação constitucional de 1992 até janeiro de 2010 é chamado pela historiografia angolana de II. República. Foi neste período que se deu o fim da terrível guerra civil que assolou o país, quando em 2002, "o Governo angolano e a UNITA assinaram o Memorando de Entendimento do Luena que pôs fim ao conflito militar."15 Finalmente, em 2010 iniciou-se o que se chama de III. República, a qual se estende até os dias atuais, com a entrada em vigor da vigente Constituição da República de Angola, de 5 de fevereiro de 2010.

Em face às quebras institucionais e ao longo período de guerra civil, Angola encontra-se ainda em processo de formação e estabelecimento de suas instituições basilares. Trata-se de um Estado Unitário, com a presença, desde a democratização, de apenas um partido político no poder central (MPLA), o que faz com que se chame de um "sistema presidencial forte". Por consequência, seu processo de desconcentração é experiência bastante recente, em especial por pressão dos partidos políticos que não ascenderam ao poder central, como a UNITA, podendo-se dizer que o gradual e paulatino processo de institucionalização das autarquias locais depende de condições efetivas para tanto, o que está em processo bastante acelerado após 2018, com a tramitação do Pacote Legislativo Autárquico na Assembleia da República Angolana.

Dessa forma, o Poder Local em Angola é uma temática que está na ordem do dia, não só pelo fato de merecer consagração constitucional, mas também por estar no quadro da edificação do Estado Democrático de Direito Angolano e da descentralização do poder político, constituindo uma das fórmulas de participação dos cidadãos na vida pública.

Entretanto, é importante ressaltar que, no ordenamento jurídico angolano, especificamente na Constituição da República de 2010, o conceito de Administração local não tem o mesmo significado que o conceito de Poder Local. Como afirma Teixeira,

${ }^{15}$ ARAÚJO, Raul. A Evolução Constitucional das Justiças de Angola. In: SANTOS, Boaventura de Sousa; VAN DÚNEN, José Octávio Serra (Orgs.). Sociedade e Estado em Construção: desafios do direito e da democracia em Angola. v. I. Coimbra: Almedina, 2012. p. 165. 
ao comentar o artigo 201 da Constituição da República de Angola, afirma que ela consagra o "exercício da Administração Local do Estado por órgãos desconcentrados da administração central, como propósito de assegurar, em nível local, a realização das atribuições e interesses específicos da administração do Estado na respectiva circunscrição administrativa, respeitando a autonomia do poder local". ${ }^{16}$ Por ser um modelo de Estado Unitário, Angola conta com um poder central, e com entidades desconcentradas de poder em âmbito local, todas elas subordinadas à administração central. Contudo, no texto constitucional de 2010 é clara a intenção de conquistar uma descentralização administrativa gradual, com a efetiva criação de Municipalidades (por eles chamadas de Autarquias Locais), todas autônomas perante o poder central, com personalidade jurídica própria e competências definidas por lei. Sobre a organização administrativa de Angola, veja-se:

A organização administrativa que hoje vigora em Angola pode ser descrita, em síntese, da seguinte maneira: existem ao todo, no território do Estado angolano, dezoito Províncias. Essas Províncias (as mesmas que existiam quando foi proclamada a independência) subdividem-se em Municípios, de que há em Angola um número total de cento e sessenta e quatro. Dentro de cada Município estão as Comunas, havendo ao todo quinhentas e cinquenta e sete dessas circunscrições no território nacional. Dentro destas Comunas, nas zonas urbanas encontram-se os Bairros; para além dos Bairros há, no território, aglomerados populacionais dispersos, situados fora das zonas urbanas, que em Angola se denominam Povoações. Depois de um longo período de centralização, que uma 1. República pós-colonial não só não esbateu, mas intensificou, durante a 2. República têm sido reatados os esforços incipientes de, por um lado, uma desconcentração administrativa e, por outro lado, uma descentralização efetiva dessa administração de pessoas e territórios em Angola. Os ritmos desse duplo processo de descentralização e de desconcentração não têm sido regulares, nem podem ser confundidos; mas a tendência para a intensificação de ambas não deixa margem para dúvidas. De par com este processo em duas calhas de esbatimento do centralismo estadual que até há bem pouco tempo fora habitual em Angola, verificamos hoje alguns esforços, apoiados numa disposição constitucional, de um muitíssimo mais inovador conjunto de iniciativas que visam o reconhecimento-integração, no próprio sistema de organização administrativa nacional, das chamadas "autoridades tradicionais". Estas autoridades tendem a ser concebidas como instâncias "anteriores ao Estado", cuja legitimidade estaria ancorada em formas históricas de organização social. ${ }^{17}$

É possível dizer que o Poder Local em Angola alicerça-se, necessariamente, num Direito positivo em concreto, ainda que ele possa ser inspirando em realidades jurídicas

16 TEIXEIRA, Carlos. Administração e governação local em Angola. Revista Debates e Tendências, v. 11, n. 1, Passo Fundo, jan./jun. 2011. p. 47.

17 GUEDES, Armando Marques et. al. Pluralismo e Legitimação: a edificação pós-colonial de Angola. Coimbra: Almedina, 2003. p. 109-110. 
alheias e de contextos históricos ou políticos de outrem. E nesse sentido, Angola diferencia-se do Brasil pois tem reconhecido de maneira explícita o Poder Local em sua Constituição Republicana de 2010, diferentemente do Brasil, o qual está presente no ordenamento jurídico de maneira implícita, com a elevação do município a ente federativo e a descentralização prevista na Constituição Federal de 1988, em especial em seu artigo 18 e 30, agregada à instrumentos de participação do cidadão no exercício do poder político (artigo 1, parágrafo único; artigo 14 e outros dispositivos dispersos na Constituição e ordenamento jurídico infraconstitucional). ${ }^{18}$

Assim, o Poder Local, à luz da vigente Constituição da República de Angola, de 2010, é um fenômeno da esfera do poder político alicerçado na desconcentração do poder e na participação da sociedade civil, tal com preceitua o artigo 213 e 214. 19 $^{19}$ Entretanto, apesar de a Constituição da República de Angola dar ao conceito de Poder Local um destaque e uma valência tridimensional, ao consagrar e institucionalizar explicitamente três formas organizativas, que são: as autarquias locais; as instituições do poder tradicional; e outras modalidades específicas de participação dos cidadãos, conforme disposto no n. 2 do artigo 213.ํ, não é possível esquecer que se está tratando de um Estado Unitário, onde o poder central é a única fonte de poder. Há uma desconcentração de alguns de seus órgãos, mas todos estão ligados hierarquicamente ao poder central.

Seguindo José Melo Alexandrino, ${ }^{20}$ ao analisar o conceito de Poder Local na Constituição da República de Angola, talvez o que mais esteja evidenciado é a maneira como o texto constitucional assinala a dimensão do poder tradicional. Assim, para o

18 SANTIN, Janaína Rigo. Princípio Constitucional da Participação e Poder Local: Uma Análise a Partir do Ordenamento Jurídico Brasileiro, Revista da Faculdade de Direito da Universidade Agostinho Neto, n.. 10, Luanda, Angola, p. 9-27, 2011; SANTIN, Janaína Rigo. O Tratamento Histórico do Poder Local no Brasil e a Gestão Democrática Municipal. Estudos Jurídicos (UNISINOS), v. 40, p. 72-78, 2007; SANTIN, Janaína Rigo. Estado, Constituição e Administração Pública no Século XXI: novos desafios da cidadania e do Poder Local. Belo Horizonte: Arraes, 2017.

19 “ARTIGO 213. (órgãos autônomos do poder local) 1. A organização democrática do Estado ao nível local estrutura-se com base no princípio da descentralização político-administrativa, que compreende a existência de formas organizativas do poder local, nos termos da presente Constituição. 2. As formas organizativas do poder local compreendem as autarquias locais, as instituições do poder tradicional e outras modalidades específicas de participação dos cidadãos, nos termos da lei. ARTIGO 214. (Princípio da autonomia local) 1. A autonomia local compreende o direito e a capacidade efectiva de as autarquias locais gerirem e regulamentarem, nos termos da Constituição e da lei, sob sua responsabilidade e no interesse das respectivas populações, os assuntos públicos locais. 2. O direito referido no número anterior é exercido pelas autarquias locais, nos termos da lei." ANGOLA. Constituição da República Angolana de 2010. Disponível em: http://www.tribunalconstitucional.ao/uploads/\%7B9555c635-8d7c-4ea1-b7f90cd33d08ea40\%7D.pdf. Acesso em abr. 2018.

20 ALEXANDRINO, José de Melo. O poder Local na Constituição da República de Angola. Direito das Autarquias Locais - Introdução, princípios e regime comum. Separata da Revista da Faculdade de Direito da Universidade de Lisboa, Lisboa, 2010. 
autor, uma das maiores inovações da Constituição de 2010 foi incorporar o princípio do pluralismo jurídico ${ }^{21}$, compreendendo as peculiaridades da cultura angolana em particular, ao aceitar o costume como fonte do direito, capaz de preceder até mesmo ao direito estatal. Nesse sentido, foi reservado o Capítulo III do Título VI da Constituição para tratar das "Instituições do Poder Tradicional", as quais foram elevadas a entidades do Poder Local.

\subsection{Poder Tradicional}

A instituição do poder tradicional como órgão integrante do Poder Local, foi algo extremamente inovador na Constituição da República Angolana de 2010. Trata-se de reconhecer dignidade constitucional a uma realidade anteriormente já existente, na qual o costume ou direito consuetudinário das autoridades do poder tradicional orientam "desde sempre" na organização política comunitária angolana, sendo anteriores ao próprio Estado. ${ }^{22}$ Conforme entendimento de Armando Marques Guedes et.al., a previsão constitucional de reconhecer o poder das autoridades tradicionais tratou-se de inteligente decisão e mecanismo de legitimação do poder estatal. Para os autores, "é importante sublinhar a natureza e finalidades pragmáticas do diálogo entretido pelos "sobas" (este é o termo genérico usado em Angola para todos os tipos de autoridades tradicionais) com o Estado: uma interlocução muitas vezes levada a cabo por iniciativa deles mesmos, que entreveem agora uma nova maneira de, através deste,

${ }^{21}$ Apesar de se entender que o princípio do pluralismo é de matriz democrática, é preciso combater uma visão ideal do pluralismo jurídico, visto que nem sempre ele pode corresponder a avanços sociais e democráticos. Na coerente visão de Boaventura de Sousa Santos, "a meu ver, não há nada intrinsecamente bom, democrático, progressista ou emancipatório no 'pluralismo jurídico'. Há até exemplos de pluralismos jurídicos bem reacionários, de que foram exemplos trágicos os Estados coloniais e a África do Sul no tempo do apartheid. E nos nossos dias há ordens jurídicas não estatais que são mais despóticas do que a ordem jurídica estatal do país em que operam (por exemplo, o direito da Máfia no sul da Itália, o direito dos gangs nas favelas do Rio de Janeiro ou de Medellin). Daí que prefiramos falar de pluralidade de ordens jurídicas em vez de pluralismo jurídico sempre que nos referimos a questões tradicionalmente associadas a esta expressão." SANTOS, Boaventura de Sousa. Direito e Justiça num país libertado há pouco do colonialismo e ainda há menos da guerra civil, em transição democrática, em desenvolvimento, rico em petróleo (por alguns anos) e diamantes, pobre para a grande maioria dos cidadãos, cultural, étnica e regionalmente muito diverso. In: SANTOS, Boaventura de Sousa; VAN DÚNEN, José Octávio Serra. Sociedade e Estado em Construção: desafios do direito e da democracia em Angola. Coimbra: Almedina, 2012. p. 46. Para um maior aprofundamento do princípio do pluralismo jurídico ver: WOLKMER, Antônio Carlos. Pluralismo Jurídico: Fundamentos de uma Nova Cultura no Direito. 2o ed. São Paulo: Editora Alfa Ômega, 1997.

22 Conforme Fernando dos Anjos Kapoco e Sérgio Nojiri, "Atualmente, a maioria dos Estados da África negra vive em situação de pluralismo jurídico. O direito oficial, o das codificações calcadas nos modelos europeus, é o dos grupos dirigentes. A maioria da população vive segundo outros direitos, ora consuetudinários, ora recentes, ignorados ou parcialmente reconhecidos pelo direito oficial." KAPOCO, Fernando dos Anjos; NOJIRI, Sérgio. "Pluralismo Jurídico: o Estado e as Autoridades Tradicionais em Angola". Revista Direito e Praxis, Rio de Janeiro, Vol. 10, N.03, 2019, p. 1898. 
se legitimarem (ou melhor, acumularem um suplemento de legitimidade) perante as "suas" populações". 23

Com todas as dificuldades de implantação de um Estado centralizado em Angola após a guerra civil, é difícil imaginar a imposição de um ordenamento jurídico sem o reconhecimento do direito costumeiro preexistente e das autoridades locais. Assim, "O Estado soberano angolano, tal como outros um pouco por toda a África, aceitou reconhecer a eficácia das autoridades 'tradicionais' na sua herança de intermediação com muitos dos grupos locais e regionais distribuídos pelo extenso território." ${ }^{24}$ Nas palavras de Carlos Feijó,

esse poder impõe-se por si, pela sua própria génese histórica, pelo que o reconhecimento do poder local em Angola é fruto da 'autodeterminação' dos povos autóctones e uma necessidade político-social e cultural de um poder que representa essas comunidades tradicionais (...) Trata-se, assim, do exercício de um poder com base nos princípios fundamentais da ancestralidade, ética, religiosidade e identidade cultural desse povo. (...) as autoridades tradicionais são vistas pelos membros das respectivas comunidades como entidades 'místicas', em contacto com realidades divinas ou sobrenaturais. ${ }^{25}$

Por serem consideradas no direito constitucional e administrativo angolano como órgãos, as autoridades tradicionais são centros de emanação de vontade com força jurídica. Conforme artigo 224 da Constituição Angolana, "personificam e exercem o poder no seio da respectiva organização político-comunitária tradicional, de acordo com os valores e normas consuetudinários e no respeito pela Constituição e pela lei". Assim, as decisões tomadas de forma participativa na comunidade e lideradas pelo "Soba" ou líder tradicional devem ser reconhecidas pelo Estado e prevalecer na solução do caso concreto, desde que, conforme a Constituição Angolana, artigo 233, n. 2, não sejam conflitantes com a Constituição nem com a dignidade da pessoa humana.

(...) titulares de uma adentrum potestas com idoneidade divina, espiritual e moral, que lhes atribui a faculdade de serem detentoras de uma espécie de poder paternal na comunidade, o que lhes confere a natureza de um ente representante da comunidade: a desobediência tem como sanção severa maldição dos antepassados, de Deus ou dos deuses e da comunidade em geral, não só sobre a pessoa do agente mas também sobre a família e sua geração. É o que denominamos, na falta de melhor, por coercibilidade mística. Ou seja, o carácter de obrigatoriedade das decisões do Soba radica

23 GUEDES, Armando Marques et. al. Pluralismo e Legitimação: a edificação pós-colonial de Angola. Coimbra: Almedina, 2003. p. 79-80.

24 GUEDES, Armando Marques et. al. Pluralismo e Legitimação: a edificação pós-colonial de Angola. Coimbra: Almedina, 2003. p. 96.

${ }^{25}$ FEIJÓ, Carlos. A Coexistência Normativa entre o Estado e as Autoridades Tradicionais na Ordem Jurídica Plural Angolana. Coimbra: Almedina, 2012. p. 32. 
no temor da comunidade em relação à sua autoridade mística, à sua natureza carismática e ao poder representativo ancestral e como que divino, i.e., na coercibilidade mística (...) As decisões são precedidas de processos participativos: reunidos em makotas, os membros da comunidade fazem-se representar e emitem opiniões sobre o assunto a decidir. ${ }^{26}$

No entendimento de Muafuani ${ }^{27}$ as Autoridades tradicionais são pessoas jurídicas anteriores ao Estado, de carácter costumeiro (tradicional), reconhecidas pelas instituições oficiais do Estado pelas funções específicas que desempenham no seio das respectivas comunidades. Há, portanto, uma definição com independência das suas atividades, sem sujeição à hierarquia ou à superintendência do Governo. Do cotejo desta definição o autor extrai os seguintes termos, que definem melhor o poder tradicional:

a) Pessoas Jurídicas. As autoridades tradicionais, apesar de estarem, em regra, representadas por uma pessoa física, não são formadas apenas pelo seu titular. O reconhecimento não é subjetivo, mas sim objectivo. O estado não reconhece o individuo, reconhece a instituição que o individuo representa, ou seja, na perspetiva da organização administrativa, o Estado reconhece a instituição Autoridade Tradicional.

b) Pré-estaduais. As autoridades tradicionais constituem realidades existentes antes do aparecimento do Estado. Isto quer dizer que o Estado não reconhece como sendo Autoridade Tradicional uma realidade "tradicional" que the é contemporânea.

c) De caracter costumeiro. As autoridades tradicionais regem-se, desde a sua constituição, pelas regras costumeiras. É claro que depois do reconhecimento estarão igualmente submetidas ao direito positivo do Estado, sobretudo em conformidade com a Constituição da República de Angola (CRA).

d) Reconhecidas pelo Estado. As autoridades tradicionais são reconhecidas e não criadas pelo Estado. Este reconhecimento deriva do facto das autoridades tradicionais existir antes do surgimento do Estado. 0 Estado não cria: reconhece esta instituição que é anterior a ele. Assim, fica descartada qualquer possibilidade de surgirem ex novo autoridades tradicionais;

e) Pelas funções específicas que desempenham. As, autoridades tradicionais são reconhecidas pelo Estado, não só pelas funções culturais ou tradicionais que desempenham, mas também pelo papel relevante que têm noutras áreas da vida na comunidade, tais como na área económica, social e de organização administrativa. ${ }^{28}$

${ }^{26}$ FEIJÓ, Carlos. A Coexistência Normativa entre o Estado e as Autoridades Tradicionais na Ordem Jurídica Plural Angolana. Coimbra: Almedina, 2012. p. 32-33 (grifos do autor)

27 MUAFUANI, Francisco Alberto. Os Desafios Da Administração Pública. Revista da Faculdade de Direito da Universidade Agostinho Neto. n. 1, out. 2013. p. 117.

28 MUAFUANI, Francisco Alberto. Os Desafios Da Administração Pública. Revista da Faculdade de Direito da Universidade Agostinho Neto. n. 1, out. 2013. p. 117. (grifo do autor) 
Assim como qualquer outra fonte de poder, o poder tradicional também possui uma estrutura orgânica, apresentada por Israel Jacob Massuanganhe, o qual afirma que é composta pelo líder comunitário, pelo conselho local e pelos conselheiros. ${ }^{29}$

Assim, para a formação das instituições estatais, a história angolana exigiu o reconhecimento do pluralismo jurídico advindo do poder tradicional em convivência paralela ao direito estatal. A falta de poderes públicos, em certas regiões, fez com que as autoridades tradicionais fossem chamadas a exercer funções administrativas, tornandoas socialmente um poder autônomo, onde quando não convivem em conjunto com os representantes estatais, transformam-se em representantes das administrações locais do Estado. Devido a estas complexidades, a Constituição da República Angolana de 2010 reconhece nas autoridades tradicionais um dos elementos principais do Poder Local.

\subsection{Modalidades Específicas de Participação: CACS (Conselhos de Auscultação e} Concertação Social)

No que tange às modalidades específicas de participação dos cidadãos na Administração Local do Estado, legalmente consagrados no ordenamento jurídico angolano no âmbito municipal pode-se apontar: o Conselho Municipal de Auscultação

\footnotetext{
29 “a) Líder comunitário - o líder comunitário, quer rei, soba ou seculo, goza de autoridade tradicional própria no exercício das suas funções e atribuições. O líder comunitário deve ser alguém com uma descendência local e com domínio dos laços que vinculam o passado das comunidades locais, exercendo o poder legitimado ou por elo político. O líder comunitário representa os interesses da comunidade locais, poderá ter como funções: - representar a comunidade local; • zelar pelo cumprimento das normas do direito costumeiro e das demais aplicáveis; • orientar as atividades comunitárias no seio da circunscrição; • representar administrativamente os interesses da comunidade local; • encaminhar as informações solicitadas pela administração local; • convocar o conselho local. b) O conselho local - o conselho local é o órgão deliberativo, representativo colegial, de consulta e auscultação, composto por todos os conselheiros e chefiado pelo líder comunitário. O conselho tem como principais funções: • analisar e emitir pareceres sobre matérias de especialidade; • acompanhar a execução dos diferentes projetos em curso na região; • acompanhar as atividades administrativas no seio da comunidade; • analisar o funcionamento e direção das estruturas do poder tradicional; • emitir parecer quanto à criação e à extinção das estruturas do poder tradicional; - deliberar sobre outras matérias de interesse da comunidade local. c) Os conselheiros: os conselheiros são individualidades de reconhecido mérito no seio da comunidade, pela valência da sua experiência, domínio das crenças e hábitos culturais, que apoiam o líder comunitário nas suas funções. Os conselheiros, no exercício das suas atividades, têm funções delegadas do líder comunitário em razão da ala que se entenda que deverá passar a ser supervisionada pelo conselheiro. Os conselheiros, dentre os serviços, podem se ocupar com a celebração de casamentos tradicionais, os rituais tradicionais, a arrecadação dos tributos locais, a gestão de terras e meio ambiente e tarefas mínimas na escala administrativa. Ressalva-se que autonomia tributária não pode ser confundida com autonomia financeira, na medida em que os projetos de investimento na circunscrição da autoridade tradicional estão previstos na matriz dos projetos da administração local do Estado ou da administração autárquica e, por conseguinte, esta região é parte integrante da administração local, sendo que a gestão é que vai obedecer a uma delegação, a autoridade local." MASSUANGANHE, Israel Jacob. O poder local, as autoridades tradicionais e a reforma da governação local: as relações do poder e os desafios no quadro da descentralização. Revista Debates e Tendências, edição especial, v. 1, n. 2, Passo Fundo, jul./dez. 2011. p. 147-148.
} 
da Comunidade, o Conselho Municipal de Concertação Social, o Conselho Municipal de Vigilância Comunitária e a Comissão de Moradores.

Por ordem cronológica, será inicialmente abordada a Lei n. 7/16, de 1 de junho, a qual veio a estabelecer a organização e o funcionamento das Comissões de Moradores. Esta lei definiu o regime jurídico das comissões, que são pessoas coletivas de direito público, resultantes da união voluntária e organização de pessoas residentes numa determinada rua, quarteirão, bairro, aldeia ou povoação. São apartidárias e sem fins lucrativos, e visam promover uma cultura de associativismo e promover o princípio da participação dos cidadãos na sua respectiva circunscrição territorial ou administrativa. ${ }^{30}$

A Comissão de Moradores será dotada de autonomia administrativa e financeira, podendo também ter autonomia política, com a eleição de seus membros pela própria comunidade residente na área de implantação da comissão. Tem por função a resolução de problemas comuns dos moradores, a promoção da participação, da solidariedade e da cooperação na comunidade, a defesa dos interesses comuns aos moradores e a melhoria de sua qualidade de vida. É constituída por uma Assembleia, uma Administração e um Conselho Fiscal.

Dentre as competências da Comissão de Moradores está a cooperação com os órgãos da Administração Local do Estado e com as autarquias locais, em especial no que tange à identificação de moradores nacionais e estrangeiros, possibilitando a denúncia de imigrantes ilegais, de igrejas e seitas ilegais; promover a limpeza e manutenção dos espaços verdes, bem como denunciar construções não autorizadas, ocupação ilegal de terrenos e práticas de comércio ilegal; questões de segurança e ordem pública; trânsito rodoviário local; poluição sonora; fazer a vigilância sanitária, veterinária e comunitária, alertando sobre desastres e calamidades naturais; assim como na identificação e controlo do grau de criminalidade e de outras formas de violação da lei e da ordem pública.

As comissões de moradores representarão os moradores daquela circunscrição territorial, podendo exercer o direito de petição perante órgãos do governo, direito de

\footnotetext{
30 Apesar de haver críticas por parte da oposição, que gostaria que as comissões de moradores fizessem parte do pacote legislativo que está em discussão em Angola para criação das autarquias locais, e não de uma lei esparsa, alertam do receio de que tais comissões poderiam se assemelhar aos antigos CAPs (Comités de Aç̧ão do Partido), com intuito de vigiar e policiar os cidadãos. Tal posição não foi predominante, e aprovou-se em 1 de junho de 2016 a referida lei. ANGOLA. Nova Lei da Comissão de Moradores Gera Controvérsia. Disponível em: https://www.voaportugues.com/a/angola-lei-comissao-demoradores/3300510.html. Acesso em 13 set. 2018.
} 
resolver pela via da conciliação conflitos entre membros da comunidade, promover ações culturais, desportivas, recreativas, de preservação ambiental e qualidade dos espaços públicos, dentre outras.

Porém, é importante ressaltar que o Poder central é o competente para definir as áreas e limites geográficos das comissões de moradores. Exerce tutela administrativa sobre elas, bem como pode determinar a destituição ou dissolução dos órgãos sociais da comissão de moradores em caso de violação à Constituição e aos Estatutos da Comissão.

Por sua vez, também como outras formas de participação dos cidadãos angolanos, tem-se a recente Lei n. 15/16, de 12 de setembro, que estabelece os princípios e normas de organização e funcionamento dos órgãos da Administração Local do Estado. Esta lei substituiu os antigos Conselhos de Auscultação e Concertação Social (CACS), anteriormente criados pelo Decreto-Lei n. 02/2007, de 3 de janeiro, que foi posteriormente revogado pela Lei n. 17/10, de 29 de julho. Nas palavras de Nelson Pestana, os antigos CACS eram tidos como uma importante "forma de organização e participação dos cidadãos, sendo um dos 'pilares' do processo de transição para a democracia". ${ }^{31}$ Tratam-se de

(...) uma oportunidade para os cidadãos poderem fazer-se ouvir nas suas reivindicações e demandas, bem como para contribuírem para resolver os problemas da gestão da res publica, favorecendo uma melhoria significativa na prestação de serviços públicos às comunidades e populações e na qualificação da governação local. Os CACS foram logo identificados como um "novo espaço de participação" dos cidadãos e uma tentativa do estado se aproximar dos governados, constituindo um espaço de debate participativo das políticas públicas locais que seria um laboratório das autarquias locais e um meio de garantir uma transição do estado centralizado à autonomia autárquica, do municipalismo da administração ao municipalismo dos cidadãos, sendo, por isto, um importante avanço na institucionalização do diálogo entre as administrações locais e as comunidades e um pressuposto crucial para a exigência de uma governação local democrática. ${ }^{32}$

Entretanto, após a mudança legislativa os antigos CACS (Conselhos Municipais de Ascultação e Concertação Social) foram extintos, e substituídos pelos: a) Conselhos Municipais de Auscultação da Comunidade; b) o Conselho Municipal de Concertação Social; e c) o Conselho Municipal de Vigilância Comunitária.

31 PESTANA, Nelson. Os Novos Espaços de Participação em Angola. In: FAURÉ, Ives-A; RODRIGUES, Cristina UdesImann. (Org.) Descentralização e Desenvolvimento Local em Angola e Moçambique: processos, terrenos e atores. Coimbra: Almedina, 2011. p. 183.

32 PESTANA, Nelson. Os Novos Espaços de Participação em Angola. In: FAURÉ, Ives-A; RODRIGUES, Cristina UdesImann. (Org.) Descentralização e Desenvolvimento Local em Angola e Moçambique: processos, terrenos e atores. Coimbra: Almedina, 2011. p. 190. 
Por conseguinte, as instituições do Poder Local angolanas, como os Conselhos acima referidos e as Comissões de Moradores são, na sua dimensão, um poder político. Todavia, não são soberanos (não podendo ameaçar a soberania do Estado unitário), devendo conviver com outros poderes, públicos, tradicionais e privados, assim como outros poderes administrativos do Estado, especialmente o de controle, nos termos previstos no artigo $241 .^{33}$ da Constituição.

Trata-se da "consequência prática da aplicação do princípio da descentralização administrativa" e também do "princípio da autonomia local", que compreende, conforme o artigo 214, n. 1 da Constituição da República de Angola, "o direito e a capacidade efectiva de as autarquias locais gerirem e regulamentarem, nos termos da Constituição e da lei, sob sua responsabilidade e no interesse das respectivas populações, os assuntos públicos locais". ${ }^{34}$

Porém, entende-se que estas constantes alterações legislativas nas instituições participativas angolanas, por mais que se tente aprimorá-las, acabam por prejudicar sua consolidação na prática cotidiana das comunidades.

\subsection{Autarquias Locais}

Atualmente, é o artigo 217..$^{35}$ da Constituição da República de Angola de 2010 que conceitualiza as autarquias locais como pessoa coletiva territorial, correspondente ao conjunto de residentes em certas circunscrições dos territórios nacional que asseguram a prossecução de interesses específicos resultantes da vizinhança, mediante

\footnotetext{
33 ARTIGO 241. (Presidente da República) (...) 4. A organização e o funcionamento da administração do Estado, bem como os poderes sobre a administração indirecta do Estado e sobre a administração autónoma, devem adequar -se ao disposto na presente Constituição." ANGOLA. Constituição da República Angolana de 2010. Disponível em: http://www.tribunalconstitucional.ao/uploads/\%7B9555c635-8d7c-4ea1b7f9-0cd33d08ea40\%7D.pdf. Acesso em abr. 2018.

34 GOUVEIA, Jorge Bacelar. Direito Constitucional de Angola. Lisboa: Instituto de Direito de Língua Portuguesa, 2014. p. 565.

35 “CAPÍTULO II- Autarquias Locais - Artigo 217. (Autarquias Locais) 1. As autarquias locais são pessoas colectivas territoriais correspondentes ao conjunto de residentes em certas circunscrições do território nacional e que asseguram a prossecução de interesses específicos resultantes da vizinhança, mediante órgãos próprios representativos das respectivas populações. 2. A organização e o funcionamento das autarquias locais, bem como a competência dos seus órgãos, são regulados por lei, de harmonia com o princípio da descentralização administrativa. 3. A lei define o patrimônio das autarquias locais e estabelece o regime de finanças locais tendo em vista a justa repartição dos recursos públicos pelo Estado e pelas autarquias, a necessária correç̧ão de desigualdades entre autarquias e a consagração da arrecadação de receitas e dos limites de realização de despesas. 4. As autarquias locais dispõem de poder regulamentar próprio, nos termos da lei." ANGOLA. Constituição da República Angolana de 2010. Disponível em: http://www.tribunalconstitucional.ao/uploads/\%7B9555c635-8d7c-4ea1-b7f9-0cd33d08ea40\%7D.pdf. Acesso em abr. 2018.
} 
órgãos representativos eleitos pelas populações. Podem estar localizadas nos Municípios, subssumindo-se neles, ou mesmo ser supra ou inframunicipais.

Salienta-se que até o momento as autarquias locais são órgãos desconcentrados da Administração Estatal, ou seja, não possuem autonomia administrativa, política, legislativa ou financeira. Entretanto, pelo princípio do gradualismo (artigo 242 da Constituição da República Angolana) $)^{36}$ o que se persegue em Angola é a concretização da Constituição, que deve caminhar para a efetiva descentralização administrativa e o reconhecimento de autonomia para as autarquias locais, que podem ser municipais, inframunicipais ou supramunicipais.

Nesse sentido, em 2018, o então Presidente da República angolano, João Manuel Gonçalves Lourenço, ouvido o Conselho da República, fez um pronunciamento à nação, sobre a realização pela primeira vez das eleições autárquicas no País, em 2020. Esse pronunciamento deu início às movimentações para criar as condições essenciais para concretização deste desiderato, executadas pelo atual Presidente angolano, João Manuel Gonçalvez Lourenço.

Assim, nos meses de junho e julho de 2018 o Ministério da Administração do Território e Reforma do Estado angolano desencadeou uma intensa campanha de auscultação dos cidadãos, a fim de elaborar de maneira conjunta com a sociedade civil um pacote legislativo capaz de dar suporte à descentralização efetiva e instituição das autarquias locais em Angola. Isso se daria de maneira gradual, a partir de alguns Municípios que seriam escolhidos conforme seu grau de autonomia e desenvolvimento. Como resultado de todo trabalho levado a cabo por várias instituições coletivas e singulares, elaborou-se em 2018 o "Pacote Legislativo Autárquico", com vistas à organização e o funcionamento das autarquias locais em Angola ${ }^{37}$.

É nesta base que a Assembleia Nacional aprovou em maio de 2019, em reuniões plenárias na generalidade, 3 projetos de lei, provenientes de dois partidos políticos (UNITA e CASA CE) e 7 propostas de lei provenientes do governo, as quais comportam o pacote legislativo autárquico e que, neste momento, tem merecido o devido tratamento

\footnotetext{
${ }^{36}$ Artigo 242. 1. A institucionalização efectiva das autarquias locais obedece ao princípio do gradualismo. 2. Os órgãos competentes do Estado determinam por lei a oportunidade da sua criação, o alargamento gradual das suas atribuições, o doseamento da tutela de mérito e a transitoriedade entre a administração local do Estado e as autarquias locais. ANGOLA. Constituição da República Angolana de 2010. Disponível em: http://www.tribunalconstitucional.ao/uploads/\%7B9555c635-8d7c-4ea1-b7f9-0cd33d08ea40\%7D.pdf. Acesso em abr. 2018.

37 ANGOLA. Proposta de Leis do Pacote Legislativo Autárquico. Distribuída de forma impressa em evento público ocorrido em agosto de 2018 no auditório do Tribunal Constitucional Angolano, em Luanda, Angola.
} 
nas comissões especializadas competentes em razão da matéria da Assembleia Nacional, a fim de serem apreciados e a posterior aprovação final, e deste modo conformar as sete leis de suporte às autarquias locais que se organizam nos municípios. Os diplomas (Projetos e propostas de lei), acima referidos resumem-se no seguinte:

- Lei Orgânica sobre a Organização e Funcionamento das Autarquias Locais;

- Lei das Finanças Locais;

- Lei Orgânica sobre as Eleições Autárquicas;

- Lei sobre a Institucionalização das Autarquias Locais;

- Lei da Tutela Administrativa sobre as Autarquias Locais.

- Lei da Transferência de Atribuições e Competências do Estado para as Autarquias Locais;

- Lei sobre o Regime geral das Taxas das Autarquias Locais;

Estas propostas de leis pretendem, efetivamente, estabelecer critérios e objetivos a serem observados no âmbito descentralização dos órgãos de Poder Local angolanos, com a criação de autarquias locais em seus Municípios. Essa descentralização, sem prejudicar a integridade e unidade territorial do Estado no tocante ao exercício do poder político e administrativo, visa promover a boa governação, já que conta com o benefício da aproximação da administração pública aos administrados, bem como facilita a participação da comunidade no processo de governação, democratizando a administração pública. Afinal, só há Poder Local quando se tem um alto grau de autonomia administrativa e financeira. Isto é, quando forem alargadas as competências, atribuições e responsabilidades das autarquias locais, quando forem dotadas dos meios humanos e técnicos necessários e quando não forem excessivamente controladas pela tutela administrativa e financeira do poder central. Para tanto, precisa haver também uma garantia ao exercício da autonomia, a fim de proteger as autarquias locais contra eventuais abusos que possam existir por parte dos órgãos de tutela, a fim de lhes ser permitido recorrer contenciosamente das ilegalidades cometidas no exercício do poder tutelar central.

\section{Conclusão}

No Brasil, a democratização erigida com a Constituição Federal de 1988 foi francamente municipalista, conferindo ao ente municipal prerrogativas com objetivo de melhor atendimento às necessidades da população. No contexto da "Constituição cidadã", o Poder Local ganha ares de ferramenta propulsora de uma gestão operativa e eficaz, 
maximizando a participação dos munícipes na tomada de decisão e no controle da atividade pública.

As garantias oferecidas pela Carta Constituinte de 1988, aliadas ao fortalecimento da descentralização administrativa ao elevar o Município a ente federativo, fomentam, na sociedade civil brasileira, a avidez por participar da formulação e execução de políticas e serviços voltados à coletividade. Porém, deve-se atentar que nos países onde o modelo descentralizador apontou resultados positivos, de uma maneira ou outra, o Poder Local já era uma realidade vivificada em sua história. A simples importação desse modelo ao sistema brasileiro não é garantia nenhuma de sua real eficácia, em especial quando há um federalismo fiscal bastante injusto com a entidade municipal, já que a maioria do bolo tributário brasileiro se concentra na União, apesar do grande elenco de atribuições municipais conferidas pela Constituição Federal de 1988.

Por sua vez, a Constituição da República de Angola de 2010, no seu art. 8.으 define a característica do Estado angolano como uma República unitária que respeita, na sua organização, os princípios da autonomia dos órgãos do Poder Local e da desconcentração e descentralização administrativas, nos termos da constituição e da lei.

Entretanto, em Angola a descentralização prevista para as autarquias locais é ainda um ideal a ser alcançado. Atualmente os governadores Provinciais e Administradores municipais, assim como os seus Adjuntos, são nomeados ou indicados pela suas entidades superiores. Não existe eleições em nível Provincial ou Municipal, embora a Constituição vigente na República de Angola prevê a implementação das autarquias locais e que estas serão assentes nos municípios. Assim, pelo sistema hierárquico presente em uma desconcentração, a administração municipal é fiscalizada pelo governo Provincial, e o exercício do governo provincial é fiscalizada pelo governo central, não existindo um órgão colegial específico para o fiscalizar dentro da estratosfera da província e do município.

Já as autoridades do poder tradicional em Angola, como órgãos do Poder Local, são constitucionalmente referenciadas e protegidas, pois elas existem antes mesmo da formação do Estado angolano. São fatores de resistência à opressão colonial portuguesa e holandesa, que a todo custo as tentou extinguir. Seu direito consuetudinário é reconhecido e de valor superior ao direito estatal, somente não preponderando quando violar a Constituição angolana e a dignidade humana. 
Assim, a temática proposta no presente artigo foi abordar o Poder Local no Brasil e em Angola, com suas aproximações e desafios. Tratar de uma das maiores preocupações das sociedades contemporâneas, que é a descentralização da atividade administrativa com vistas à democratização do poder e à aproximação dos cidadãos da gestão pública.

Mas não basta apenas criar-se mecanismos formais. O direito é positivado com a finalidade de se tornar efetivo no universo social. Mas, para tanto, é necessário que o Poder Público cumpra com os mandamentos constitucionais e legais que the são impostos, criando e implementando possibilidades de uma gestão pública democrática.

E, por sua vez, é necessária a participação da cidadania na gestão pública e no controle social, a fim de não contentar-se, somente, a ser mero espectador, para tornarse agente ativo no processo de administração da coisa pública.

A democracia brasileira e também a angolana serão melhores se a cidadania nestes países também for aperfeiçoada constantemente. E este é um grande desafio que merece ser enfrentado por ambos os países, com vistas ao seu desenvolvimento e democratização.

\section{Referências Bibliográficas}

ALEXANDRINO, José de Melo. "O poder Local na Constituição da República de Angola". Direito das Autarquias Locais - Introdução, princípios e regime comum. Separata da Revista da Faculdade de Direito da Universidade de Lisboa, Lisboa, 2010.

ANGOLA. Constituição da República Angolana de 2010. Disponível em: http://www.tribunalconstitucional.ao/uploads/\%7B9555c635-8d7c-4ea1-b7f90cd33d08ea40\%7D.pdf. Acesso em abr. 2018.

ANGOLA. Nova Lei da Comissão de Moradores Gera Controvérsia. Disponível em: https://www.voaportugues.com/a/angola-lei-comissao-de-moradores/3300510.html. Acesso em 13 set. 2018.

ANGOLA. Proposta de Leis do Pacote Legislativo Autárquico. Distribuída de forma impressa em evento público ocorrido em agosto de 2018 no auditório do Tribunal Constitucional Angolano, em Luanda, Angola. 
ARAÚJO, Raul. "A Evolução Constitucional das Justiças de Angola". In: SANTOS, Boaventura de Sousa; VAN DÚNEN, José Octávio Serra (Orgs.). Sociedade e Estado em Construção: desafios do direito e da democracia em Angola. v. I. Coimbra: Almedina, 2012.

DOWBOR, Ladislau. O que é poder local. São Paulo: Brasiliense, 1994.

FEIJÓ, Carlos. A Coexistência Normativa entre o Estado e as Autoridades Tradicionais na Ordem Jurídica Plural Angolana. Coimbra: Almedina, 2012.

GOUVEIA, Jorge Bacelar. Direito Constitucional de Angola. Lisboa: Instituto de Direito de Língua Portuguesa, 2014.

GUEDES, Armando Marques et. al. Pluralismo e Legitimação: a edificação pós-colonial de Angola. Coimbra: Almedina, 2003.

HESSE, Konrad. A força normativa da constituição. Tradução de: Gilmar Ferreira Mendes. Porto Alegre: Sérgio Antonio Fabris, 1991.

KAPOCO, Fernando dos Anjos; NOJIRI, Sérgio. "Pluralismo Jurídico: o Estado e as Autoridades Tradicionais em Angola". Revista Direito e Praxis, Rio de Janeiro, v. 10, n.03, 2019, pp. 1889-1931.

LEAL, Rogério Gesta. Direito urbanístico: condições e possibilidades da constituição do espaço urbano. Rio de Janeiro: Renovar, 2003.

MASSUANGANHE, Israel Jacob. "O poder local, as autoridades tradicionais e a reforma da governação local: as relações do poder e os desafios no quadro da descentralização." Revista Debates e Tendências, edição especial, v. 1, n. 2, Passo Fundo, jul./dez. 2011.

MOÁS, Luciane da Costa. Cidadania e poder local. Rio de Janeiro: Lumen Juris, 2002.

MUAFUANI, Francisco Alberto. "Os Desafios Da Administração Pública". Revista da Faculdade de Direito da Universidade Agostinho Neto. n. 1, out. 2013.

OLIVEIRA, Cláudio Ladeira de; ARAÚJO JÚNIOR, Miguel Etinger de. "Democracia participativa e plano diretor dos municípios". In: XV Congresso Nacional do CONPEDI, 2007, Belo Horizonte. Anais do XV Congresso Nacional do CONPEDI. Florianópolis : 
Boiatex, 2007. v. $1 . \quad$ p. 6631-6648. Disponível em http://www.conpedi.org/manaus/arquivos/anais/bh/claudio_ladeira_de_oliveira.pdf. Acesso em 16 ago. 2019.

PESTANA, Nelson. "Os Novos Espaços de Participação em Angola". In: FAURÉ, Ives-A; RODRIGUES, Cristina UdesImann. (Org.) Descentralização e Desenvolvimento Local em Angola e Moçambique: processos, terrenos e atores. Coimbra: Almedina, 2011.

RTP Notícias. População de Angola sobe para mais de 25,7 milhões de pessoas. Disponivel em: https://www.rtp.pt/noticias/mundo/populacao-de-angola-sobe-paramais-de-257-milhoes-de-pessoas_n906065. Acesso em 08 fev. 2018.

SANTIN, Janaína Rigo. Estado, Constituição e Administração Pública no Século XXI: novos desafios da cidadania e do Poder Local. Belo Horizonte: Arraes, 2017.

SANTIN, Janaína Rigo. "O Tratamento Histórico do Poder Local no Brasil e a Gestão Democrática Municipal”. Estudos Jurídicos (UNISINOS), v. 40, p. 72-78, 2007

SANTIN, Janaína Rigo. "Princípio Constitucional da Participação e Poder Local: Uma Análise a Partir do Ordenamento Jurídico Brasileiro". Revista da Faculdade de Direito da Universidade Agostinho Neto, n.o 10, Luanda, Angola, p. 9-27, 2011

SANTOS, Boaventura de Sousa. "Direito e Justiça num país libertado há pouco do colonialismo e ainda há menos da guerra civil, em transição democrática, em desenvolvimento, rico em petróleo (por alguns anos) e diamantes, pobre para a grande maioria dos cidadãos, cultural, étnica e regionalmente muito diverso." In: SANTOS, Boaventura de Sousa; VAN DÚNEN, José Octávio Serra. Sociedade e Estado em Construção: desafios do direito e da democracia em Angola. Coimbra: Almedina, 2012.

SANTOS, Boaventura de Sousa; VAN DÚNEN, José Octávio Serra. Sociedade e Estado em Construção: desafios do direito e da democracia em Angola. Coimbra: Almedina, 2012.

SARTORI, Giovanni. Teoría de la Democracia: 2. Los problemas clásicos. Tradução de: Santiago Sánchez González. Madrid: Alianza Editorial, 1997.

TEIXEIRA, Carlos. "Administração e governação local em Angola". Revista Debates $e$ Tendências, v. 11, n. 1, Passo Fundo, jan./jun. 2011. 
WOLKMER, Antônio Carlos. Pluralismo Jurídico: Fundamentos de uma Nova Cultura no Direito. 2o ed. São Paulo: Editora Alfa Ômega, 1997.

\begin{abstract}
Sobre os autores

\section{Janaína Rigo Santin}

Possui Pós-Doutorado em Direito Administrativo pela Universidade de Lisboa, Portugal, com bolsa CAPES, pelo período de 8 meses (2011). Doutorado em Direito pela Universidade Federal do Paraná (2004). Mestrado em Direito pela Universidade Federal de Santa Catarina (2000). Advogada e Professora Titular da Universidade de Passo Fundo, nas disciplinas de direito municipal, direito urbanístico e direito das obrigações. Faz parte do corpo docente permanente do Mestrado em Direito e do Mestrado e Doutorado em História da Universidade de Passo Fundo. É professora colaboradora do Mestrado em Ciências Jurídicas-Econômicas e Desenvolvimento e do Mestrado em Governação e Gestão Pública da Universidade Agostinho Neto, em Luanda, Angola-África. É professora colaboradora do Programa de Pós-Graduação em Direito Ambiental da Universidade de Caxias do Sul. E-mail: janainars@upf.br
\end{abstract}

\title{
Carlos Teixeira
}

Juiz do Tribunal Constitucional Angolano. Doutorando pela Faculdade de Direito da Universidade de Coimbra. Mestre em Direito, pela Faculdade de Direito da Universidade de Coimbra. Diretor do Centro de Pesquisas em Políticas Públicas e Governação Local da Faculdade de Direito da Universidade Agostinho Neto (desde 7 de setembro de 2009). E-mail: cteixeira1611@hotmail.com

Os autores contribuíram igualmente na redação do artigo. 